\title{
Obese trauma patients have increased need for dialysis
}

\author{
Ahmed Farhat $^{1}$ (D) Areg Grigorian ${ }^{1} \cdot$ Ninh T. Nguyen ${ }^{1} \cdot$ Brian Smith $^{1} \cdot$ Barbara J. Williams ${ }^{1} \cdot$ Sebastian D. Schubl ${ }^{1}$. \\ Victor Joe ${ }^{1}$. Dawn Elfenbein ${ }^{1}$. Jeffry Nahmias ${ }^{1}$
}

Received: 22 February 2019 / Accepted: 11 May 2019 / Published online: 20 May 2019

(c) Springer-Verlag GmbH Germany, part of Springer Nature 2019

\begin{abstract}
Purpose Obesity is a risk factor for the development of acute kidney injury but its effect on the need for dialysis in trauma has not been elucidated. Additionally, the contribution that obesity has towards risk of mortality in trauma is unclear. We hypothesized that patients with a higher body mass index (BMI) will have a higher risk for need of dialysis and mortality after trauma.

Methods This is a retrospective analysis using the National Trauma Data Bank. All patients $\geq 8$ years old were grouped based on BMI: normal $\left(18.5-24.99 \mathrm{~kg} / \mathrm{m}^{2}\right)$, obese $\left(30-34.99 \mathrm{~kg} / \mathrm{m}^{2}\right)$, severely obese $\left(35-39.99 \mathrm{~kg} / \mathrm{m}^{2}\right)$ and morbidly obese $\left(\geq 40 \mathrm{~kg} / \mathrm{m}^{2}\right)$. The primary outcome was hemodialysis initiation. The secondary outcome was mortality during the index hospitalization.

Results From 988,988 trauma patients, 571,507 (57.8\%) had a normal BMI, 233,340 (23.6\%) were obese, 94,708 (9.6\%) were severely obese, and $89,433(9.0 \%)$ were morbidly obese. The overall rate of hemodialysis was $0.3 \%$. After adjusting for covariates, we found that obese (OR 1.36, CI 1.22-1.52, $p<0.001$ ), severely obese (OR 1.89, CI 1.66-2.15, $p<0.001$ ) and morbidly obese (OR 2.04, CI 1.82-2.29, $p<0.001$ ) patients had a stepwise increased need for hemodialysis after trauma. Obese patients had decreased (OR 0.92, CI 0.88-0.95, $p<0.001$ ), severely obese had similar (OR 1.02, CI 0.97-1.08, $p=0.50$ ) and morbidly obese patients had increased (OR 1.06, CI 1.01-1.12, $p=0.011$ ) risk of mortality after trauma.

Conclusions Obesity was associated with an increased risk for dialysis after trauma. Mortality risk was reduced in obese, similar in severely obese, and increased in morbidly obese trauma patients suggesting an inflection threshold BMI for risk of mortality in trauma.
\end{abstract}

Keywords Obesity $\cdot$ Trauma $\cdot$ Dialysis $\cdot$ Renal replacement therapy $\cdot$ Acute kidney injury

\section{Introduction}

Nearly $40 \%$ of adults in the United States are obese and, if current trends continue, over $50 \%$ will be obese by 2030 [1, 2]. Previous reports have shown that obesity is associated with an increased risk for mortality in trauma patients [3, 4] but this has not been consistently reported in the literature $[5,6]$. However, the sole systematic review on this topic by Liu et al. [7] found that obesity was strongly associated with an increased risk of mortality following trauma.

Ahmed Farhat

amfarhat@uci.edu

1 Division of Trauma, Burns and Surgical Critical Care, Department of Surgery, University of California, Irvine Medical Center, 333 The City Blvd West, Suite 1600, Orange, CA 92868-3298, USA
Obesity increases the risk of developing diabetes (DM) and hypertension (HTN) which are the leading causes of end-stage renal disease (ESRD) $[8,9]$. Obesity is also a risk factor for the development of acute kidney injury (AKI), which, if severe enough, requires dialysis [10]. Multiple modalities of dialysis exist including intermittent hemodialysis, peritoneal dialysis, and continuous renal replacement therapy (CRRT) [11].

The rate of AKI after trauma ranges between 6 and 37\% and the rate of dialysis after trauma is as high as $8 \%$ depending on the severity of injuries [12-18]. Hypovolemia/hemorrhagic shock, severe sepsis, and comorbidities such as HTN, DM, and pre-existing renal impairment are the most common risk factors implicated in the development of AKI requiring dialysis [19-21]. As much as one-third of the cases of renal failure in the trauma population may be the result 
of inadequate resuscitation leading to poor renal perfusion $[22,23]$.

Shashaty et al. [24] found that a BMI $\geq 30 \mathrm{~kg} / \mathrm{m}^{2}$ is associated with a nearly fivefold increased risk for AKI in a population of trauma patients. However, the association of BMI and need for dialysis in trauma patients remains unclear. We hypothesized that patients with a higher BMI will have a higher risk for need of dialysis, as well as mortality after trauma.

\section{Methods}

A retrospective analysis using the National Trauma Data Bank (NTBD) was performed. Since patient height and body weight were included in the NTDB beginning in 2013, we analyzed data from January 1, 2013 to December 31, 2015. All patients $\geq 18$ years old were included. Patients were grouped based on their BMI: normal (18.5-24.99 kg/ $\mathrm{m}^{2}$ ), obese (30-34.99 kg/m²), severely obese (35-39.99 kg/ $\left.\mathrm{m}^{2}\right)$ and morbidly obese $\left(\geq 40 \mathrm{~kg} / \mathrm{m}^{2}\right)$. Patients with history of chronic renal failure were excluded from the logistic regression analysis since the NTDB defines these patients as requiring periodic peritoneal dialysis, hemodialysis, hemofiltration, or hemodiafiltration. The primary outcome was the need for new in-hospital hemodialysis, defined by international classification of diseases (ICD) version-9 procedure code 39.95. The secondary outcome was in-hospital mortality. Demographic variables collected included age, gender, race, and comorbidities. The injury profile included injury severity score (ISS), mechanism of injury, and associated injuries such as traumatic brain injury (TBI), kidney trauma (i.e. laceration, parenchymal injury and renal hilum injury), pelvis fracture, and upper/lower extremity fractures. The rate of nephrectomy and other urological procedures were collected as well. These were defined by the appropriate ICD-9 diagnosis and procedure codes.

All variables were coded as present or absent. Descriptive statistics were performed for all variables. A Mann-Whitney $U$ test was used to compare continuous variables and chi square was used to compare categorical variables. Categorical data were reported as percentages, and continuous data were reported as medians with interquartile range or means with standard deviation. The magnitude of the association between predictor variables and need for new dialysis was first measured using a univariable logistic regression model. Covariates for dialysis were chosen based on a review of the literature and included age, ISS, Trauma and Injury Severity Score (TRISS), Glasgow Coma Scale (GCS) score on admission, severe lower extremity injury with Abbreviated Injury Score (AIS) $>3$, crush injury, burn injury, and history of alcohol abuse, HTN, congestive heart failure (CHF), and
DM [15, 25-29]. Covariates for mortality were also chosen based on a review of the literature and included age, ISS, TRISS, GCS, and history of HTN, CHF, DM, and TBI [29-33]. Covariates with statistical significance $(p<0.20)$ were included in the hierarchical multivariable logistic regression models and the adjusted risks for dialysis and mortality were reported with odds ratios (OR) and 95\% confidence intervals (CI). The reference group used in our analyses included trauma patients with a normal BMI. We excluded patients with direct renal trauma and those that underwent nephrectomy in the analysis for risk of new dialysis. All $p$ values were two sided, with a statistical significance level of $<0.05$. All analyses were performed with IBM SPSS Statistics for Windows (Version 24, IBM Corp., Armonk, NY).

\section{Results}

\section{Demographics}

There were 988,988 patients included in the study. Of these patients, 571,507 (57.8\%) had a normal BMI, $233,340(23.6 \%)$ were obese $\left(30-34.99 \mathrm{~kg} / \mathrm{m}^{2}\right), 94,708$ $(9.6 \%)$ were severely obese $\left(35-39.99 \mathrm{~kg} / \mathrm{m}^{2}\right)$, and $89,433(9.0 \%)$ were morbidly obese $\left(\geq 40 \mathrm{~kg} / \mathrm{m}^{2}\right)$. Compared to those with normal BMI $\left(18.5-24.99 \mathrm{~kg} / \mathrm{m}^{2}\right)$, patients that were obese were older (median age, 53 vs 52 years, $p<0.001)$ and more often male $(63.9 \%$ vs $58.0 \%, p<0.001)$. Obese patients also had higher rates of DM $(18.1 \%$ vs $8.2 \%, p<0.001)$, HTN $(38.1 \%$ vs $27.6 \%$, $p<0.001)$, and kidney injury $(1.4 \%$ vs $1.2 \%, p<0.001)$ but less TBI $(27.6 \%$ vs $30.5 \%, p<0.001)$ and a similar rate of nephrectomy $(0.1 \%$ vs $0.1 \%, p=0.87)$ and median ISS (9 vs $9, p=0.35$ ). Severely obese patients were of similar age (53 vs 52 years, $p=0.11$ ) with less males ( $57.6 \%$ vs $58.0 \%$, $p<0.001)$ when compared to patients with a normal BMI. Additionally, severely obese patients had higher rates of DM $(23.5 \%$ vs $8.2 \%, p<0.001)$, HTN $(42.5 \%$ vs $27.6 \%$, $p<0.001)$, and kidney injury (1.4\% vs $1.2 \%, p<0.001)$, lower rate of TBI $(25.4 \%$ vs $30.5 \%, p<0.001)$ and median ISS ( 8 vs $9, p<0.001$ ), and a similar rate of nephrectomy $(0.1 \%$ vs $0.1 \%, p=0.29)$. Morbidly obese patients were of similar age (52 vs $52, p=0.14$ ) and less often male (51.8\% vs $58.0 \%, p<0.001)$ compared to patients with a normal BMI. Rates of DM ( $24.7 \%$ vs $8.2 \%, p<0.001)$, HTN $(42.3 \%$ vs $27.6 \%, p<0.001)$, and kidney injury $(1.4 \%$ vs $1.2 \%, p<0.001$ ) were all higher in morbidly obese patients. However, the morbidly obese group had less TBI ( $24.1 \%$ vs $30.5 \%, p<0.001)$, lower median ISS (8 vs 9 , $p<0.001)$, and a similar rate of nephrectomy $(0.1 \%$ vs $0.1 \%, p=0.14$ ) (Table 1$)$. 
Table 1 Demographics of adult trauma patients stratified by body mass index

\begin{tabular}{|c|c|c|c|c|c|c|c|}
\hline Characteristics & $\operatorname{Normal}^{\mathrm{a}}(n=571,507)$ & Obese $(n=233,340)$ & $p$ values & $\begin{array}{l}\text { Severely obese } \\
(n=94,708)\end{array}$ & $p$ values & $\begin{array}{l}\text { Morbidly obese } \\
(n=89,433)\end{array}$ & $p$ values \\
\hline $\begin{array}{l}\text { Age (years), median } \\
\text { (IQR) }\end{array}$ & $52.0(45)$ & $53.0(32)$ & $<0.001$ & $53.0(29)$ & 0.11 & $52.0(30)$ & 0.14 \\
\hline Sex (male), $n(\%)$ & $331,257(58.0 \%)$ & $148,943(63.9 \%)$ & $<0.001$ & $54,565(57.6 \%)$ & $<0.05$ & $46,272(51.8 \%)$ & $<0.001$ \\
\hline \multicolumn{8}{|l|}{ Race, $n(\%)$} \\
\hline White & $418,887(73.3 \%)$ & $171,956(73.7 \%)$ & $<0.001$ & $69,682(73.6 \%)$ & 0.07 & $64,908(72.6 \%)$ & $<0.001$ \\
\hline Asian & $13,683(2.4 \%)$ & $1953(0.837 \%)$ & $<0.001$ & $561(0.592 \%)$ & $<0.001$ & $559(0.625 \%)$ & $<0.001$ \\
\hline Black & $79,927(14.0 \%)$ & $30,874(13.2 \%)$ & $<0.001$ & $13,929(14.7 \%)$ & $<0.001$ & $13,798(15.4 \%)$ & $<0.001$ \\
\hline \multicolumn{8}{|l|}{ Comorbidities, $n(\%)$} \\
\hline Diabetes & $47,059(8.2 \%)$ & $42,232(18.1 \%)$ & $<0.001$ & $22,275(23.5 \%)$ & $<0.001$ & $22,076(24.7 \%)$ & $<0.001$ \\
\hline Hypertension & $157,736(27.6 \%)$ & $88,983(38.1 \%)$ & $<0.001$ & $40,293(42.5 \%)$ & $<0.001$ & $37,860(42.3 \%)$ & $<0.001$ \\
\hline $\mathrm{CHF}$ & $18,103(3.2 \%)$ & $8665(3.7 \%)$ & $<0.001$ & $4384(4.6 \%)$ & $<0.001$ & $5153(5.8 \%)$ & $<0.001$ \\
\hline Alcohol abuse & $55,191(9.7 \%)$ & $15,676(6.7 \%)$ & $<0.001$ & $5026(5.3 \%)$ & $<0.001$ & $4838(5.4 \%)$ & $<0.001$ \\
\hline ISS, median (IQR) & $9.0(8)$ & $9.0(8)$ & 0.35 & $8.0(7)$ & $<0.001$ & $8.0(7)$ & $<0.001$ \\
\hline $\begin{array}{l}\text { Blunt mechanism, } \\
n(\%)\end{array}$ & $478,642(83.7 \%)$ & $195,520(83.8 \%)$ & $<0.001$ & $79,792(84.2 \%)$ & $<0.001$ & $76,046(85.0 \%)$ & $<0.001$ \\
\hline \multicolumn{8}{|l|}{ Injuries, $n(\%)$} \\
\hline TBI & $174,568(30.5 \%)$ & $64,460(27.6 \%)$ & $<0.001$ & $24,036(25.4 \%)$ & $<0.001$ & $21,568(24.1 \%)$ & $<0.001$ \\
\hline Kidney injury & $6831(1.2 \%)$ & $3280(1.4 \%)$ & $<0.001$ & $1355(1.4 \%)$ & $<0.001$ & $1283(1.4 \%)$ & $<0.001$ \\
\hline Pelvic fracture & $42,691(7.5 \%)$ & $14,758(6.3 \%)$ & $<0.001$ & $5965(6.3 \%)$ & $<0.001$ & $5867(6.6 \%)$ & $<0.001$ \\
\hline $\begin{array}{l}\text { Upper extremity } \\
\text { fracture }\end{array}$ & $97,839(17.1 \%)$ & $46,030(19.7 \%)$ & $<0.001$ & $18,958(20.0 \%)$ & $<0.001$ & $17,336(19.4 \%)$ & $<0.001$ \\
\hline $\begin{array}{l}\text { Lower extremity } \\
\text { fracture }\end{array}$ & $141,727(24.8 \%)$ & $60,765(26.0 \%)$ & $<0.001$ & $27,086(28.6 \%)$ & $<0.001$ & $27,845(31.1 \%)$ & $<0.001$ \\
\hline \multicolumn{8}{|l|}{ Procedure, $n(\%)$} \\
\hline Nephrectomy & $398(0.1 \%)$ & $182(0.1 \%)$ & 0.87 & $63(0.1 \%)$ & 0.29 & $75(0.1 \%)$ & 0.14 \\
\hline $\begin{array}{l}\text { Other urological } \\
\text { operations }\end{array}$ & $39,949(7.0 \%)$ & $17,370(7.4 \%)$ & $<0.001$ & $7041(7.4 \%)$ & 0.003 & $10,981(12.3 \%)$ & $<0.001$ \\
\hline
\end{tabular}

Normal: BMI $18.5-24.99 \mathrm{~kg} / \mathrm{m}^{2}$, obese: BMI 30-34.99 kg/m², severely obese: BMI 35-39.99 kg/m², morbidly obese: BMI $\geq 40 \mathrm{~kg} / \mathrm{m}^{2}$ $B M I$ body mass index, IQR interquartile range, $C H F$ congestive heart failure, ISS injury severity score, $T B I$ traumatic brain injury

${ }^{\mathrm{a}}$ Reference group

\section{Primary outcomes}

Compared to those with a normal BMI, patients in the obese $(0.3 \%$ vs $0.2 \%, p<0.001)$, severely obese $(0.5 \%$ vs $0.2 \%, p<0.001)$, and morbidly obese groups $(0.6 \%$ vs $0.2 \%, p<0.001)$ all required dialysis at a higher rate. In a univariable logistic regression model, BMI $\geq 35 \mathrm{~kg} / \mathrm{m}^{2}$ was associated with a greater need for dialysis (OR 3.03, CI $2.72-3.38, p<0.001$ ). The strongest variable associated with a need for dialysis was severe sepsis (OR 44.78, CI 40.85-49.07, $p<0.001$ ) followed by ARDS (OR 26.85, CI 24.44-29.51, $p<0.001$ ) (Table 2). After adjusting for covariates in a multivariable logistic regression model, obese (OR 1.36, CI 1.22-1.52, $p<0.001$ ), severely obese (OR 1.89, CI $1.66-2.15, p<0.001$ ), and morbidly obese (OR 2.04, CI 1.82-2.29, $p<0.001$ ) patients had a stepwise increased risk for dialysis (Table 3 ).

\section{Other clinical outcomes in trauma patients stratified by BMI}

After adjusting for covariates in a multivariable logistic regression model for mortality, obese (OR 0.92, CI $0.88-0.95, p<0.001$ ), severely obese (OR 1.02, CI $0.97-1.08, p=0.49$ ) and morbidly obese (OR 1.06, CI $1.01-1.08, p=0.011)$ patients had decreased, similar, and increased risks of mortality after trauma, respectively, compared to those with a normal BMI (Table 4). Obese (median days, 4.0 vs $3.0, p<0.001$ ), severely obese (median days, 4.0 vs $3.0, p<0.001$ ), and morbidly obese patients (median days, 4.0 vs $3.0, p<0.001$ ) all had a longer hospital LOS when compared to patients with a normal BMI. However, none of the groups had a significantly longer ICU LOS $(p>0.05)$. A higher rate of obese $(0.7 \%$ vs $0.5 \%, p<0.001)$, severely obese $(1.1 \%$ 
Table 2 Univariate logistic regression analysis for need for dialysis in trauma victims 18 years of age and older

\begin{tabular}{lccc}
\hline Predictors & Odds ratio & Confidence interval & $p$ value \\
\hline BMI $\geq 35$ & 3.03 & $2.72-3.38$ & $<0.001$ \\
Age $\geq 65$ years & 1.72 & $1.62-1.84$ & $<0.001$ \\
Ventilatory days $>2$ & 22.61 & $21.27-24.04$ & $<0.001$ \\
Required exploratory laparotomy & 10.13 & $9.33-11.00$ & $<0.001$ \\
Comorbidities & & & $<0.001$ \\
Alcohol abuse & 1.42 & $1.28-1.57$ & $<0.001$ \\
Hypertension & 2.12 & $2.00-2.25$ & $<0.001$ \\
CHF & 4.06 & $3.70-4.44$ & $<0.001$ \\
Diabetes & 3.84 & $3.60-4.10$ & $<0.001$ \\
Injuries & & & $<0.001$ \\
ISS $\geq 25$ & 6.81 & $6.35-7.31$ & $<0.001$ \\
Kidney injury & 6.19 & $5.50-6.96$ & $<0.05$ \\
AIS-lower extremity & a & $8.98-21.94$ & $<0.001$ \\
Crush injury & 14.03 & $1.21-2.70$ & $<0.001$ \\
Burn injury & 1.81 & $2.27-2.92$ & $<0.001$ \\
Complications & 2.58 & & $<0.001$ \\
Compartment syndrome & & $11.89-17.56$ & $24.44-29.51$ \\
ARDS & 14.45 & $40.85-49.07$ & \\
Severe sepsis & 26.85 & & \\
\hline PI & 44.78 & & \\
\hline
\end{tabular}

$B M I$ body mass index (units $\mathrm{kg} / \mathrm{m}^{2}$ ), $C H F$ congestive heart failure, ISS injury severity score, $A I S$ abbreviated injury score, $A R D S$ adult respiratory distress syndrome

${ }^{\text {a }}$ Severe (grade $\left.>3\right)$
Table 3 Adjusted analysis for need for dialysis in trauma victims 18 years of age and older stratified by body mass index (BMI)

\begin{tabular}{llll}
\hline $\mathrm{BMI}^{\mathrm{a}}$ & Odds ratio & Confidence interval & $p$ value \\
\hline Obese & 1.36 & $1.22-1.52$ & $<0.001$ \\
Severely obese & 1.89 & $1.66-2.15$ & $<0.001$ \\
Morbidly obese & 2.04 & $1.82-2.29$ & $<0.001$ \\
\hline
\end{tabular}

Controlled for age, alcohol use, history of hypertension, congestive heart failure, diabetes, severe abbreviated injury score-lower extremity grade $(>3)$, crush injury, burn injury, injury severity score, heart rate, systolic blood pressure, respiratory rate and Glasgow Coma Scale score on admission

Patients with direct renal trauma (i.e. laceration, parenchymal injury, renal hilum injury) and those that underwent nephrectomy excluded

Obese: BMI 30-34.99 kg/m², severely obese: BMI 35-39.99 kg/m², morbidly obese: $\mathrm{BMI} \geq 40 \mathrm{~kg} / \mathrm{m}^{2}$

${ }^{a}$ Reference group includes patients with normal BMI (18.5-24.99 kg/ $\mathrm{m}^{2}$ )

vs $0.5 \%, p<0.001)$, and morbidly obese $(1.1 \%$ vs $0.5 \%$, $p<0.001)$ patients developed AKI, compared to those with normal BMI. The rate of mortality was lower in obese $(2.8 \%$ vs $3.0 \%, p<0.001)$ and severely obese $(2.9 \%$ vs $3.0 \%, p=0.02)$ patients compared to those with a normal BMI. Morbidly obese patients had similar rates of mortality $(3.1 \%$ vs $3.0 \%, p=0.08)$ compared to normal BMI patients (Table 5).
Table 4 Adjusted analysis for mortality in trauma victims 18 years of age and older stratified by body mass index (BMI)

\begin{tabular}{lllc}
\hline $\mathrm{BMI}^{\mathrm{a}}$ & Odds ratio & Confidence interval & $p$ value \\
\hline Obese & 0.92 & $0.88-0.95$ & $<0.001$ \\
Severely obese & 1.02 & $0.97-1.08$ & 0.50 \\
Morbidly obese & 1.06 & $1.01-1.12$ & 0.011 \\
\hline
\end{tabular}

Controlled for age, history of hypertension, congestive heart failure, diabetes, injury severity score, traumatic brain injury, heart rate, systolic blood pressure, respiratory rate and Glasgow Coma Scale score on admission

Obese: BMI 30-34.99 kg/m², severely obese: BMI $35-39.99 \mathrm{~kg} / \mathrm{m}^{2}$, morbidly obese: $\mathrm{BMI} \geq 40 \mathrm{~kg} / \mathrm{m}^{2}$

${ }^{\text {a }}$ Reference group includes patients with normal BMI (18.5-24.99 kg/ $\mathrm{m}^{2}$ )

\section{Discussion}

This retrospective analysis using 3 years of data from the NTDB was the first to demonstrate a stepwise increased risk in the need for dialysis after trauma with increasing BMI while controlling for many well-known risk factors for acute renal failure. Also, obese, severely obese, and morbidly obese patients had a decreased, similar, and increased risk of mortality, respectively, compared to those 
Table 5 Clinical outcomes of adult trauma patients stratified by body mass index

\begin{tabular}{|c|c|c|c|c|c|c|c|}
\hline Outcome & Normal $^{\mathrm{a}}(n=571,507)$ & Obese $(n=233,340)$ & $p$ values & $\begin{array}{l}\text { Severely obese } \\
n=94,708\end{array}$ & $p$ values & $\begin{array}{l}\text { Morbidly obese } \\
(n=89,433)\end{array}$ & $p$ values \\
\hline $\begin{array}{l}\text { LOS (days), median } \\
\text { (IQR) }\end{array}$ & $3.0(4)$ & $4.0(4)$ & $<0.001$ & $4.0(5)$ & $<0.001$ & $4.0(5)$ & $<0.001$ \\
\hline $\begin{array}{l}\text { ICU (days), median } \\
\text { (IQR) }\end{array}$ & $3.0(3)$ & $3.0(4)$ & 0.38 & $3.0(5)$ & 0.28 & $3.0(4)$ & 0.56 \\
\hline $\begin{array}{l}\text { Ventilator days, median } \\
\text { (IQR) }\end{array}$ & $3.0(6)$ & $3.0(7)$ & 0.41 & $3.0(8)$ & 0.37 & $3.0(8)$ & 0.42 \\
\hline $\begin{array}{l}\text { Required major surgery, } \\
n(\%)\end{array}$ & $249,748(43.7 \%)$ & $109,844(47.1 \%)$ & $<0.001$ & $46,018(48.6 \%)$ & $<0.001$ & $44,619(49.9 \%)$ & $<0.001$ \\
\hline Needed dialysis, $n(\%)$ & $1135(0.2 \%)$ & $786(0.3 \%)$ & $<0.001$ & $454(0.5 \%)$ & $<0.001$ & $548(0.6 \%)$ & $<0.001$ \\
\hline \multicolumn{8}{|l|}{ Complications, $n(\%)$} \\
\hline AKI & $2681(0.5 \%)$ & $1842(0.7 \%)$ & $<0.001$ & $1049(1.1 \%)$ & $<0.001$ & $1101(1.1 \%)$ & $<0.001$ \\
\hline ARDS & $2939(0.5 \%)$ & $1686(0.7 \%)$ & $<0.001$ & $738(0.8 \%)$ & $<0.001$ & $776(0.8 \%)$ & $<0.001$ \\
\hline Severe sepsis & $2153(0.4 \%)$ & $1166(0.5 \%)$ & $<0.001$ & $547(0.6 \%)$ & $<0.001$ & $541(0.6 \%)$ & $<0.001$ \\
\hline Mortality, $n(\%)$ & $17,265(3.0 \%)$ & $6556(2.8 \%)$ & $<0.001$ & $2728(2.9 \%)$ & 0.02 & $2797(3.1 \%)$ & 0.08 \\
\hline
\end{tabular}

Normal: BMI $18.5-24.99 \mathrm{~kg} / \mathrm{m}^{2}$, obese: BMI 30-34.99 kg/m², severely obese: BMI 35-39.99 kg/m², morbidly obese: BMI $\geq 40 \mathrm{~kg} / \mathrm{m}^{2}$ $L O S$ length of stay, IQR interquartile range, $I C U$ intensive care unit, $A K I$ acute kidney injury, $A R D S$ acute respiratory distress syndrome ${ }^{\text {a }}$ Reference group

with a normal BMI while controlling for many well-known risk factors for death in trauma patients.

The association of obesity and AKI has previously been established; however, the association of obesity and need for dialysis in trauma patients has remained unclear. Multiple studies have reported that shock commonly associated with major trauma leads to inadequate renal perfusion and subsequent AKI $[22,23]$. Glance et al. demonstrated that severely obese trauma patients have a 2.5- to 4-fold higher risk of developing severe AKI compared to non-obese patients [34]. Our study expands on these findings by demonstrating an approximately 20-30\% stepwise increase in need for dialysis with each subsequently more obese category. One possible explanation for this is that obese patients are proportionally under resuscitated. Nelson et al. found that obese trauma patients received significantly lower volumes of both crystalloid and colloid intravenous fluids after correcting for BMI when compared to their normal-weight counterparts [35]. Similarly, Adams et al. found that obese septic patients received significantly lower vasopressor and fluid doses by weight when compared to their non-obese counterparts [36]. Another possible explanation may be that the chronic inflammatory state seen in obese patients may increase the risk of AKI. Obese patients have higher baseline levels of pro-inflammatory mediators such as interleukin-6 which has been shown to increase the risk of developing AKI [20, 37-39]. Additionally, obese patients are at a significantly higher risk of developing intra-abdominal hypertension (IAH) which also has been postulated as a potential explanation for the increased risk of AKI in this group [40-43]. IAH can lead to renal venous congestion and an effective hypovolemic state due to decreased venous return thereby increasing the risk of developing AKI [40]. A final possible explanation is that obese patients are more likely to have undiagnosed pre-existing comorbidities that predispose them to AKI. Lai et al. suggested that pre-existing comorbidities including chronic kidney disease (CKD) may be the primary risk factor for AKI following trauma [19, 44]. According to a study done in 2017 by the Center for Disease Control and Prevention, $96 \%$ of adults in the United States with kidney damage or mildly reduced kidney function are unaware of having CKD. Furthermore, $48 \%$ of those with severely reduced kidney function who are not on dialysis are also unaware of having CKD [45]. Obesity is a well-documented risk factor for kidney disease thus obese patients are more likely to have undiagnosed kidney damage thereby increasing their risk of requiring dialysis [46]. Future studies that include pre-trauma data and on-admission renal function laboratory evaluations are needed to evaluate this and other factors that may lead to the increased risk for dialysis in obese trauma patients.

The relationship between obesity and mortality in trauma patients is unclear. Obese trauma patients have previously been reported to have 1.5 - to 6 -fold increased mortality compared to non-obese patients [4, 47-49]. A previous report showed that severely obese trauma patients were at least $30 \%$ more likely to die and approximately twice as likely to have major complications when compared with non-obese patients [34]. A recent meta-analysis by Liu et al. compared trauma patients with $\mathrm{BMI} \geq 30 \mathrm{~kg} / \mathrm{m}^{2}$ to patients with $\mathrm{BMI}<30 \mathrm{~kg} / \mathrm{m}^{2}$ and concluded that obesity was associated with $45 \%$ 
increased odds of mortality when compared to patients who were not obese despite equivalent injury severity [7]. Our results augment these findings as we found that obese, severely obese, and morbidly obese patients have a decreased, similar, and increased risk of mortality after trauma, respectively, after controlling for welldocumented risk factors for death. This protective effect of obesity on mortality, which dissipates with increasing BMI, has been demonstrated in burn patients and other surgical fields such as vascular, colorectal, and cardiac surgery [50-54]. Some have suggested that patients with increased BMI are protected against severe injuries as the extra adipose tissue acts as a cushion and reduces damage to more vital structures $[49,55,56]$. As these studies did not differentiate among varying degrees of obesity, it is possible that this cushion effect is applicable to mildly obese patients and dissipates thereafter with the deleterious effects of severe or morbid obesity. Furthermore, the J-shaped relationship we reported between BMI and mortality may be attributed to the increased frequency of comorbidities and more complicated post-injury care inherent to patients with severe and morbid obesity [55, $57,58]$.

As a large retrospective database study, our study has many inherent limitations including reporting bias, coding errors, and missing data. In addition, the database lacks pertinent variables including the reason for dialysis initiation, timing of dialysis, number of dialysis treatments, and long-term need for dialysis. For instance, it is possible a patient received one dialysis treatment and was categorized as requiring dialysis. Furthermore, there is a lack of standardized criteria for dialysis initiation and, therefore, it is possible patients may have been placed on dialysis at one institution when they would not have required it at another. In addition, as there is no specific ICD-9 diagnosis code for CRRT, some patients who received CRRT may have been missed; although, with no alternative option, it is likely that these patients were included under ICD-9 39.95 (hemodialysis). Also, as mentioned previously there is a lack of data regarding pre-admission renal function as well as even on-arrival renal function such as a glomerular filtration rate and/ or baseline creatinine. Additionally, it is not possible to differentiate between inadequate resuscitation and refractory hypotension in trauma patients. Finally, as with all database studies, we cannot make definitive cause-andeffect statements. Despite these limitations, our study is strengthened by the large number of patients and multiple trauma centers that were included which provides generalizability to our findings. Furthermore, we are the first to demonstrate the association of obesity and need for dialysis in trauma patients.

\section{Conclusion}

After controlling for many well-known risk factors for death and ARF in trauma patients, obese patients had a decreased mortality compared to those with a normal BMI, despite a greater need for dialysis. Severely obese patients had a similar mortality compared to those with a normal BMI and an even greater need for dialysis. Finally, morbidly obese patients had an increased mortality compared to those with a normal BMI and had the greatest increased risk for dialysis. Future research is needed to confirm these findings and determine if any interventions such as weight-based resuscitation may help mitigate the increased risk for dialysis in obese trauma patients. There is also a need for a large prospective study to investigate the impact of obesity on mortality and complications such as need for dialysis, in trauma patients.

Acknowledgements The abstract for this study was presented at the 13th annual Academic Surgical Congress meeting in 2018 in Jacksonville, Florida.

Funding No funding was received for this study.

\section{Compliance with ethical standards}

Conflict of interest Ahmed Farhat, Areg Grigorian, Ninh T. Nguyen, Brian Smith, Barbara J. Williams, Sebastian D. Schubl, Victor Joe, Dawn Elfenbein, and Jeffry Nahmias declare that they have no conflict of interest.

\section{References}

1. Hales CM, Carroll MD, Fryar CD, et al. Prevalence of obesity among adults and youth: United States, 2015-2016. NCHS Data Brief. 2017;288:1-8.

2. Wang Y, Beydoin MA, Liang L, et al. Will all Americans become overweight or obese? Estimating the progression and cost of the US obesity epidemic. Obesity. 2008;16(10):2323-30 (Silver Spring).

3. Neville AL, Brown CV, Weng J, et al. Obesity is an independent risk factor of mortality in severely injured blunt trauma patients. Arch Surg. 2004;139(9):983-7.

4. Byrnes MC, McDaniel MD, Moore MB, et al. The effect of obesity on outcomes among injured patients. J Trauma. 2005;58(2):232-7.

5. Alban RF, Lyass S, Margulies DR, et al. Obesity does not affect mortality after trauma. Am Surg. 2006;72(10):966-9.

6. Milzman DP, Boulanger BR, Rodriguez A, et al. Pre-existing disease in trauma patients: a predictor of fate independent of age and injury severity score. J Trauma. 1992;32(2):236-43.

7. Liu T, Chen J, Bai X, et al. The effect of obesity on outcomes in trauma patients: a meta-analysis. Injury. 2013;44(9):1145-52. https://doi.org/10.1016/j.injury.2012.10.038 (Published Online first: 2012/12/4).

8. Mokdad AH, Ford ES, Bowman BA, et al. Prevalence of obesity, diabetes, and obesity-related health risk factors, 2001. JAMA. 2003;289(1):76-9. 
9. Ghaderian SB, Beladi-Mousavi SS. The role of diabetes mellitus and hypertension in chronic kidney disease. J Ren Inj Prev. 2014;3(4):109-10. https://doi.org/10.12861/jrip.2014.31 (Published Online first: 2014/12/1).

10. Danziger J, Chen KP, Lee J, et al. Obesity, acute kidney injury, and mortality in critical illness. Crit Care Med. 2016;44(2):328-34.

11. Pannu N, Gibney RN. Renal replacement therapy in the intensive care unit. Ther Clin Risk Manag. 2005;1(2):141-50.

12. Bagshaw SM, George C, Gibney RT, et al. A multi-center evaluation of early acute kidney injury in critically ill trauma patients. Ren Fail. 2008;30(6):581-9.

13. Eriksson M, Brattstrom O, Martensson J, et al. Acute kidney injury following severe trauma: risk factors and long-term outcome. J Trauma Acute Care Surg. 2015;79(3):407-12.

14. Skinner DL, Hardcastle TC, Rodseth RN, et al. The incidence and outcomes of acute kidney injury amongst patients admitted to a level I trauma unit. Injury. 2014;45(1):259-64.

15. Podoll AS, Kozar R, Holcomb JB, et al. Incidence and outcome of early acute kidney injury in critically-ill trauma patients. PLoS One. 2013;8:e77376.

16. Bihorac A, Delano MJ, Schold JD, et al. Incidence, clinical predictors, genomics, and outcome of acute kidney injury among trauma patients. Ann Surg. 2012;252(1):158-65.

17. Haines RW, Lin SP, Hewson R, et al. Acute kidney injury in trauma patients admitted to critical care: development and validation of a diagnostic prediction model. Sci Rep. 2018;8(1):3665. https://doi.org/10.1038/s41598-018-21929-2 (Published 2018 Feb 26).

18. Beitland S, Moen H, Os I. Acute kidney injury with renal replacement therapy in trauma patients. Acta Anaesthesiol Scand. 2010;54(7):833-40.

19. Lai WH, Rau CS, Wu SC, et al. Post-traumatic acute kidney injury: a cross-sectional study of trauma patients. Scand J Trauma Resusc Emerg Med. 2016;24(1):136. https://doi.org/10.1186/ s13049-016-0330-4 (Published 2016 Nov 22)

20. Bihorac A, Baslanti TO, Cuenca AG, et al. Acute kidney injury is associated with early cytokine changes after trauma. J Trauma Acute Care Surg. 2013;74(4):1005-13.

21. Lord JM, et al. The systemic immune response to trauma: an overview of pathophysiology and treatment. Lancet. 2014;384:1455-65.

22. Morris JA Jr, Mucha P Jr, Ross SE, et al. Acute posttraumatic renal failure: a multicenter perspective. J Trauma. 1991;31:1584-90. https://doi.org/10.1097/00005373-199112000-00003.

23. Harrois A, Libert N, Duranteau J. Acute kidney injury in trauma patients. Curr Opin Crit Care. 2017;23(6):447-56.

24. Shashaty MG, Meyer NJ, Localio AR, et al. African American race, obesity, and blood product transfusion are risk factors for acute kidney injury in critically ill trauma patients. J Crit Care. 2012;27(5):496-504.

25. Leblanc M, Kellum JA, Gibney RT, et al. Risk factors for acute renal failure: inherent and modifiable risks. Curr Opin Crit Care. 2005;11(6):533-6.

26. Koyner JL, Murray PT. Mechanical ventilation and the kidney. Blood Purif. 2009;29(1):52-68.

27. Loftus TJ, Bihorac A, Ozrazgat-Baslanti T, et al. Acute kidney injury following exploratory laparotomy and temporary abdominal closure. Shock. 2017;48(1):5-10.

28. Sykes E, Cosgrove JF. Acute renal failure and the critically ill surgical patient. Ann R Coll Surg Engl. 2007;89(1):22-9.

29. Harrois A, Soyer B, Gauss T, Hamada S, Raux M, Duranteau J. Prevalence and risk factors for acute kidney injury among trauma patients: a multicenter cohort study. Crit Care. 2018;22(1):344.

30. Sim J, Lee J, Lee JC, Heo Y, Wang H, Jung K. Risk factors for mortality of severe trauma based on 3 years' data at a single Korean institution. Ann Surg Treat Res. 2015;89(4):215-9.
31. Sammy I, Lecky F, Sutton A, et al. Factors affecting mortality in older trauma patients - a systematic review and meta-analysis. Injury. 2016;47(6):1170-83.

32. Watkins TR, Nathens AB, Cooke CR, et al. Acute respiratory distress syndrome after trauma: development and validation of a predictive model. Crit Care Med. 2012;40(8):2295-303.

33. Jin H, Liu Z, Xiao Y, Fan X, Yan J, Liang H. Prediction of sepsis in trauma patients. Burns Trauma. 2014;2(3):106-13. https ://doi.org/10.4103/2321-3868.135479 (Published 2014 Jul 28).

34. Glance LG, Li Y, Osler TM, et al. Impact of obesity on mortality and complications in trauma patients. Ann Surg. 2014;259(3):576-81.

35. Nelson J, Billeter AT, Seifert B, et al. Obese trauma patients are at increased risk of early hypovolemic shock: a retrospective cohort analysis of 1084 severely injured patients. Crit Care. 2012;16(3):77.

36. Adams C, Tucker C, Allen B, et al. Disparities in hemodynamic resuscitation of the obese critically ill septic shock patient. J Crit Care. 2017;37:219-23.

37. MacLaughlin HL, Blacklock RM, Wright K, et al. Obesity and recovery from acute kidney injury ( $\mathrm{Ob} \mathrm{AKI})$ : a prospective cohort feasibility study. BMJ Open. 2019;9:e024033.

38. Cuschieri J, Bulger E, Schaeffer V, et al. Early elevation in random plasma IL-6 following severe injury is associated with development of organ failure. Shock. 2011;34(4):346-51.

39. Eder K, Baffy N, Falus A, Fulop AK. The major inflammatory mediatory interleukin-6 and obesity. Inflamm Res. 2009;58(11):727-36.

40. Shashaty MG, Kalkan E, Bellamy SL, et al. Computed tomography-defined abdominal adiposity is associated with acute kidney injury in critically ill trauma patients. Crit Care Med. 2014;42(7):1619-28.

41. Kim IB, Prowle J, Baldwin I, Bellomo R. Incidence, risk factors and outcome associations of intra-abdominal hypertension in critically ill patients. Anaesth Intensive Care. 2012;40(1):79-89.

42. Reintam Blaser A, Parm P, Kitus R, Starkopf J. Risk factors for intra-abdominal hypertension in mechanically ventilated patients. Acta Anaesthesiol Scand. 2011;55(5):607-14.

43. Talizin TB, Tsuda MS, Tanita MT, et al. Acute kidney injury and intra-abdominal hypertension in burn patients in intensive care. Rev Bras Ter Intensiva. 2018;30(1):15-20.

44. Gettings LG, Reynolds HN, Scalea T. Outcome in post-traumatic acute renal failure when continuous renal replacement therapy is applied early vs. late. Int Care Med. 1999;25:805-13.

45. Stats F. National chronic kidney disease fact sheet, 2017. US Department of Health and Human Services, Centers for Disease Control and Prevention; 2017.

46. Kovesdy CP, Furth SL, Zoccali C, et al. Obesity and kidney disease: hidden consequences of the epidemic. Indian J Nephrol. 2017;27(2):85-92.

47. Brown CV, Neville A, Rhee P, et al. The impact of obesity on the outcomes of 1153 critically injured blunt trauma patients. J Trauma. 2005;59:1048-51.

48. Choban PS, Weireter LJ Jr, Maynes C. Obesity and increased mortality in blunt trauma. J Trauma. 1991;31(9):1253-7.

49. Arbabi S, Wahl WL, Hemmila MR, Kohoyda-Inglis C. The cushion effect. J Trauma. 2003;54(6):1090-3.

50. Jeschke MG, Finnerty CC, Emdad F, et al. Mild obesity is protective after severe burn injury. Ann Surg. 2013;258(6):1119-29.

51. De Santo LS, Moscariello C, Zebele C. Implications of obesity in cardiac surgery: pattern of referral, physiopathology, complications, prognosis. J Thorac Dis. 2018;10(7):4532-9.

52. Govaert JA, Lijftogt N, van Dijk WA, et al. Colorectal cancer surgery for obese patients: financial and clinical outcomes of a Dutch population-based registry. J Surg Oncol. 2016;113(5):489-95. 
53. Alizadeh RF, Moghadamyeghaneh Z, Whealon MD, et al. Body mass index significantly impacts outcome of colorectal surgery. Am Surg. 2016;82(10):930-5.

54. Davenport DL, Xenos ES, Hosokawa P, et al. The influence of body mass index obesity status on vascular surgery 30-day morbidity and mortality. J Vasc Surg. 2009;49(1):140-7.

55. Wang SC, Bednarski B, Patel S, et al. Increased depth of subcutaneous fat is protective against abdominal injuries in motor vehicle collisions. Assoc Adv Auto Med. 2003;47:545-59.
56. Beckmann NM, Cai C, Spence SC, et al. Is elevated body mass index protective against cervical spine injury in adults? Emerg Radiol. 2018;25(4):415-24.

57. Pi-Sunyer X. The medical risks of obesity. Postgrad Med. 2009;121(6):21-33.

58. Brown CV, Velmahos GC. The consequences of obesity on trauma, emergency surgery, and surgical critical care. World J Emerg Surg. 2006;1:27. https://doi.org/10.1186/1749-7922-1-27 (Published 2006 Sep 6). 